\title{
PERSPECTIVE \\ The Potential Impact of Scribes on Medical School Applicants and Medical Students with the New Clinical Documentation Guidelines
}

\author{
Dawn DeWitt, MD, MSC, MACP, FRACP ${ }^{1,2}$ and Leila E. Harrison, MA, MEd ${ }^{7}$ \\ ${ }^{1}$ The Department of Medical Education and Clinical Sciences, The Elson S. Floyd College of Medicine, Washington State University, Spokane, WA, \\ USA; ${ }^{2}$, Spokane, USA.
}

The presence of scribes in various specialties, including internal medicine, is being heralded as a way to decrease clinician documentation time and burnout. Many medical school applicants become scribes to understand life as a doctor and gain clinical experience. Scribing is already perceived by some as a new key to successfully gaining entrance to medical school. One season of our admissions data showed that scribes were more likely to be admitted $(\mathrm{OR}=1.61)$. Scribes may also inadvertently make it harder for medical schools to secure clinical placements for medical students. While trained scribes are highly valued by providers struggling to deal with increasing documentation burdens, supervising or training scribes also requires time that cannot be devoted to teaching. Medical documentation duties could provide valuable learning experiences for medical students. The recent ruling allowing medical students to contribute directly to clinical documentation without requiring redocumentation by supervisors gives medical schools and clinician-educators an opportunity to consider the unintended consequences of the scribe movement for medical education. Educators should consider when and how students can maximize the educational benefits of participating in patient documentation despite the templated methods commonly used in electronic health record (EHR) systems.

KEY WORDS: clinical scribe; clinical documentation; medical students; admissions; medical education.

J Gen Intern Med 33(11):2002-4

DOI: $10.1007 / \mathrm{s} 11606-018-4582-8$

(c) Society of General Internal Medicine 2018

\section{INTRODUCTION}

Scribes are increasingly common in many specialties. Despite growing calls to reduce wasteful documentation in the USA, ${ }^{1}$ real change seems elusive and scribes are providing some relief. Given the epidemic of burnout, partially attributable to the documentation burden in the USA, having a scribe could be career-saving for many physicians. ${ }^{2}$ However, there has been no published discussion on the impact of scribes on

Received October 10, 2017

Revised February 22, 2018

Accepted July 5, 2018

Published online July 31, 2018 medical student education. Additionally, no studies address the potential impact of scribing as a growing pre-medical clinical experience option. The aim of this paper is to discuss how widespread adoption of scribes might impact admissions processes and clinical learning opportunities for medical students.

The main purpose of scribes is to reduce physician documentation time. However, the presence of scribes may reduce access to clinical experiences for medical students since scribes inadvertently compete for space in examination rooms and physicians' time as required to interact with and train scribes. Importantly, the Centers for Medicare \& Medicaid Services (CMS) recently announced that students will again be allowed to contribute meaningfully to patient documentation as of March 5th, 2018, by "[allowing] the teaching physician to verify in the medical record any student documentation of components of E/M services, rather than redocumenting the work." ${ }^{3}$ This recent ruling provides an opportunity for educators to re-examine how medical students could participate in and learn from documentation responsibilities, i.e., how we design experiences that would enhance medical student knowledge and clinical reasoning skills without using students as scribes per se.

\section{Potential Implications for Medical School Applicants and Admissions Committees}

The increasing prevalence of scribes, and the opportunity for pre-medical students to work as scribes, may significantly impact medical students and admissions processes. Scribe America, the largest scribe training company in the US states, "A background in Medical Scribing is quickly becoming the standard for pre-medical experience, and is suggested by medical school acceptance committees across the country." Scribe training varies but employers generally pay for scribes to complete training. ${ }^{5}$ Scribe America provides a minimum of $120 \mathrm{~h}$ of training, including online, classroom, and clinical training while another commercial competitor describes training as including $40 \mathrm{~h}$ of coursework, EMR and facility courses, and a minimum of eight shifts at the facility with a trainer. ${ }^{6}$ Given the cost and training time, borne by health systems and providers, most practices want scribes for at least 6-12 months full-time. 
It is common knowledge that most medical schools prefer that applicants have exposure to the practice of medicine in some form prior to applying. Even an informal expectation that applicants have scribing experience, specifically, may lead to further admissions barriers for applicants. If most applicants had to do the training described above and work full-time for 6-12 months, the total time investment to become a doctor would increase by at least a year. Given that scribes earn minimum wage to $\$ 12 /$ hour, working as a scribe for any significant amount of time would further complicate debt load as well. ${ }^{7}$ While one could argue that this experience might be more beneficial than some other medical school pre-requisites, we are concerned that "scribing" may emerge as a perceived advantage or even a necessary (hidden pre-requisite) experience for entry into medical school.

A review of our de-identified 2016-2017 admissions data (Table 1) showed that the percentage of applicants with selfreported scribing experience (yes/no and reported hours) increased at each stage (OR 1.61 for receiving an admission offer). Students who had worked as scribes reported a median of over 1200 h scribing (>30 weeks @ 40 h/week). Even if scribing is not required or even mentioned in information for medical school applicants, admissions committees could become accustomed to seeing scribing experience among their applicants, setting an unfair bar for applicants without scribe experience. Furthermore, if scribing becomes a preferred way to gain clinical experience, this might disadvantage or discourage applicants who live in areas where scribing opportunities do not exist or for whom other commitments prevent them from scribing for a significant time period. This is not to deter applicants from working as scribes; rather, it is to bring awareness to potential unintended consequences of it becoming a "hidden prerequisite."

\section{Scribe Role and Overlap with Medical Student Learning Opportunities}

Ironically, scribes (as employees) are allowed to document with the training described above, but the CMS guidelines were the major issue preventing medical students (not "employed") from contributing significantly to clinical documentation until the recent announcement eliminating requirements for redocumentation (effective March 5th, 2018). ${ }^{5,8}$ Educators now need to review and discuss learning objectives, desired competencies and the appropriate role of medical student documentation as part of the clinical record and as part of their education. This is particularly pertinent in pre- clerkship preceptorships, when students are often only allowed to observe, but when careful application of the new documentation rules could allow students to participate in a more meaningful way. Teaching students to obtain information and report it appropriately is a major goal of undergraduate medical education. However, medical students need progressively challenging clinical experiences that help them develop competence in obtaining information and in appropriate documentation, and medical students should not be used only as scribes, per se. A qualitative study by Yan et al., describing the range of scribe duties and issues in their healthcare system, includes comments validating that scribes have active roles in patient care (beyond transcribing information) including developing appropriate positive relationships with patients. ${ }^{9}$ Thus, the presence of scribes may devalue medical students' data-gathering and clinical reasoning abilities and discourage them by disrupting opportunities to engage in increasing responsibility for patients.

Two studies reviewing the quality of scribe documentation found significant variation in quality. ${ }^{10,11}$ When supervisors spend time to improve scribe documentation, they are educating the scribes about appropriate use of medical language and the relative pertinence of information (e.g., choosing pertinent positives and negatives), which are also medical student milestones for developing clinical reasoning. This begs the question of whether this "training" time might be better spent with medical students.

Educators should evaluate the potential educational value to medical students of serving appropriately in a similar scribe/ assistant role during preceptorships in the pre-clerkship years, versus the all-too-common student experience of observing visits without participating significantly. Clinician educators facilitate the professional development of students and residents by giving them opportunities to practice their skills under supervision and giving them feedback on their work. As students gain competence, they should be "entrusted" with increasingly challenging tasks as they progress toward becoming independent clinicians. Given the new ruling, it makes sense to consider how much time and training should be put into helping students become expert users of electronic health record systems when they may or may not have to learn new system (s) during residency training. Assuming that students also get appropriate experience in taking histories, performing physical examinations, and writing synthetic patient notes (rather than EHR templated notes), including students in real-time documentation may facilitate pre-clerkship students'

Table 1 Applicants and Admitted Students with Scribe Experience from a 4-Week Admissions Cycle at One Medical School

\begin{tabular}{|c|c|c|c|c|c|}
\hline $\begin{array}{l}\text { Applicants in } 4 \\
\text { weeks of } 1 \text { year } \\
N=710\end{array}$ & $\begin{array}{l}\text { Reported scribe } \\
\text { experience }\end{array}$ & $\begin{array}{l}\text { Hours of scribing } \\
\text { median (range) }\end{array}$ & $\begin{array}{l}\text { Quartile } \\
1 \mathrm{~h}\end{array}$ & $\begin{array}{l}\text { Quartile } \\
3 \mathrm{~h}\end{array}$ & $\begin{array}{l}\text { Inter-quartile } \\
\text { range }\end{array}$ \\
\hline Total applicants & $192(27 \%)$ & $1300(20-8600)$ & 580 & 2240 & 1660 \\
\hline $\begin{array}{l}\text { Selected for } \\
\text { interview }\end{array}$ & $213(30 \%)$ & $1325(30-8600)$ & 738 & 2469 & 1732 \\
\hline Accepted & $26(36 \%)$ & $1255(40-8600)$ & 893 & 2427 & 1534 \\
\hline
\end{tabular}


clinical knowledge of medical vocabulary and common patient problems while facilitating more engagement with the patient and supervisor in real time.

\section{IMPACT ON WILLINGNESS AND TIME TO TEACH}

Many clinical educators and potential clinician teachers (needed for growing numbers of US medical students) now have a scribe, who has a longitudinal relationship with that clinician and their patients. Doctors spend significant energy teaching their scribes the specifics about their practice as well as training them in the intricacies of electronic record documentation and insurance requirements (something that hospital administrators wish students and residents knew more about). Conversely, some academic physicians believe scribes will allow clinician-educators to redirect documentation time to teaching. One study including teaching time as a parameter showed no change in perceptions of time spent teaching and no increase in patients seen per hour. ${ }^{12}$ The single study addressing the issue directly in ED residents reported significantly increased face-to-face teaching. ${ }^{13}$ Thus, significant research evaluating the impact of scribes on medical students and residents might examine the prevalence of scribes in academic teaching settings and ways to decrease barriers to including students.

\section{CONCLUSION}

These potential consequences of the scribe movement came to our attention as a result of our own experiences in medical education, medical school admissions, and clinical practice. ${ }^{14}$ Our perspective is limited by having admissions data from only 1 year from one medical school. We echo the calls of doctors who are pleading for reduced documentation/ administrative burdens as they face burnout or worse. It makes sense to use scribes to increase individual physicians' happiness and productivity. However, widespread use of scribes will not eliminate the underlying EHR documentation/billing issues and may create additional hurdles to medical school admission if scribing becomes an unintended expectation among pre-medical students/applicants and admissions committees. The presence of scribes may also impact teaching capacity. Teaching capacity could decrease as medical students are inadvertently excluded from exam rooms and hospital wards because doctors do not have enough time or space to include students. Conversely, scribes could increase teaching capacity at some cost, but more research is needed in both academic and community settings.

Future research might further define the trade-offs of increasing the numbers of scribes versus what the growing number of US medical students might learn about clinical reasoning, teamwork and common medical problems while contributing to documentation. Next steps might include defining learning objectives and milestones that could be mastered if students take on a bigger role in documentation, especially during pre-clerkship clinical experiences. If scribes become a ubiquitous industry standard, their contributions to the healthcare workforce may generate measurable benefits that are currently only partially defined but increasing numbers of scribes could also have significant consequences regarding clinician-teacher availability. If we can thoughtfully embrace this opportunity to discuss and research these issues, especially in light of the new CMS ruling, we may be able to increase engagement of pre-clerkship learners and decrease the burden on clinicians while avoiding potential downsides.

Corresponding Author: Dawn DeWitt, MD, MSc, MACP, FRACP; , Spokane, USA (e-mail: dawn.dewitt@wsu.edu).

\section{Compliance with Ethical Standards:}

Conflict of Interest: The authors declare that they do not have a conflict of interest.

\section{REFERENCES}

1. Erickson SM, Rockwern B, Koltov M, McLean R, for the Medical Practice and Quality Committee of the American College of Physicians. Putting Patients First by Reducing Administrative Tasks in Health Care: A Position Paper of the American College of Physicians. Ann Intern Med. 2017;166(9):659-61.

2. Wright AA, Katz IT. Beyond burnout-redesigning care to restore meaning and sanity for physicians. N Engl J Med 2018; 378:309-311. DOI: https://doi.org/10.1056/NEJMp1716845.

3. CMS Pub. 100-04, Transmittal 3971. February 2, 2018. Available at: https://www.cms.gov/Outreach-and-Education/Medicare-LearningNetwork-MLN/MLNMattersArticles/Downloads/MM10412.pdf. Accessed June 26, 2018.

4. Scribe America. What is a medical scribe? Available at: http://www. scribeamerica.com/what is medical scribe.html. Accessed June 26, 2018.

5. ScribeAmerica. Implementation FAQs. Available at: http://www. scribeamerica.com/what-we-do-faq.html\#a27. Accessed June 26, 2018.

6. Phys Assist. Training. Available at: https://www.iamscribe.com/be-ascribe/. Accessed June 26, 2018.

7. Salary REF: Bailey M. The pay is low, the typing nonstop, but the medical scribe business is booming. STATnews, April 25, 2016. Available at: https://www.statnews.com/2016/04/25/scribes-emergency-room/. Accessed June 26, 2018.

8. Reasons why Medical Students are not Permitted to Enter Information into the Electronic Health Record (EHR) System: 2013-14. https://www. aamc.org/initiatives/cir/425116/14c.html. Accessed June 26, 2018.

9. Yan C, Rose S, Rothberg MB, Mercer MB, Goodman K, Misra-Hebert AD. Physician, scribe, and patient perspectives on clinical scribes in primary care. Journal of General Internal Medicine. 2016;31(9), 990-995.

10. Pranaat R, Mohan V, O'Reilly M, Hirsh M, McGrath K, Scholl G, Woodcock D, Gold JA. Use of simulation based on an electronic health records environment to evaluate the structure and accuracy of notes generated by medical scribes: proof-of-concept study. JMIR Med Inform. 2017;5(3):e30. doi:https://doi.org/10.2196/medinform.7883.

11. Misra-Hebert AD, Amah L, Rabovsky A, Morrison S, Cantave M, Hu B, Sinsky CA, Rothberg MB. Medical scribes: how do their notes stack up? J Fam Pract. 2016;65(3): 155-9.

12. Hess JJ, Wallenstein J, Ackerman JD, Akhter M, Ander D, Keadey MT, Capes JP. Scribe impacts on provider experience, operations, and teaching in an academic emergency medicine practice. West $\mathrm{J}$ Emerg Med. 2015;16(5):602-10. doi https://doi.org/10.5811/westjem.2015.6. 25432.

13. Ou E, Mulcare $\mathbf{M}$, Clark S, Sharma $\mathbf{R}$. Implementation of scribes in an academic emergency department: the resident perspective. J Grad Med Educ. 2017;9(4):518-522. doi: https://doi.org/10.4300/JGME-D-1600807.1.

14. DeWitt DE. A tale of two countries: how I saw more patients with more joy in internal medicine practice. Ann Intern Med. 2017;166(9):669-70. 